\title{
Efficacy of an mHealth intervention to stimulate physical activity in COPD patients after pulmonary rehabilitation
}

\author{
Sigrid N.W. Vorrink ${ }^{1}$, Helianthe S.M. Kort ${ }^{1,2}$, Thierry Troosters ${ }^{3}$, Pieter Zanen ${ }^{4}$ \\ and Jan-Willem J. Lammers ${ }^{4}$
}

Affiliations: 'Utrecht University of Applied Sciences, Research Group Demand Driven Care, Utrecht, The Netherlands. ${ }^{2}$ Eindhoven University of Technology, Dept of the Built Environment, Section Building Physics and Services, Eindhoven, The Netherlands. ${ }^{3} \mathrm{KU}$ Leuven-University of Leuven, Dept of Rehabilitation Sciences, University Hospital Gasthuisberg, Respiratory Division, Leuven, Belgium. ${ }^{4}$ University Medical Centre Utrecht, Dept of Respiratory Medicine, Division Heart and Lungs, Utrecht, The Netherlands.

Correspondence: Sigrid N.W. Vorrink, Utrecht University of Applied Sciences, Research Centre for Innovations in Health Care, Heidelberglaan 7 PO Box 12011, 3501 AA, Utrecht, The Netherlands.

E-mail: sigrid.vorrinkahu.nl

ABSTRACT Physical inactivity in patients with chronic obstructive pulmonary disease (COPD) is associated with poor health status and increased disease burden. The present study aims to test the efficacy of a previously developed mobile $(\mathrm{m})$ Health intervention to improve or maintain physical activity in patients with COPD after pulmonary rehabilitation.

A randomised controlled trial was performed in 32 physiotherapy practices in the Netherlands. COPD patients were randomised into intervention or usual care groups. The intervention consisted of a smartphone application for the patients and a monitoring website for the physiotherapists. Measurements were performed at $0,3,6$ and 12 months. Physical activity, functional exercise capacity, lung function, health-related quality of life and body mass index were assessed.

157 patients started the study and 121 completed it. There were no significant positive effects of the intervention on physical activity (at 0 months: intervention $5824 \pm 3418$ steps per weekday, usual care $5717 \pm 2870$ steps per weekday; at 12 months: intervention $4819 \pm 2526$ steps per weekday, usual care $4950 \pm 2634$ steps per weekday; $\mathrm{p}=0.811$ ) or on the secondary end-points. There was a significant decrease over time in physical activity $(\mathrm{p}<0.001)$, lung function $(\mathrm{p}<0.001)$ and mastery $(\mathrm{p}=0.017)$, but not in functional exercise capacity $(\mathrm{p}=0.585)$.

Although functional exercise capacity did not deteriorate, our mHealth intervention did not improve or maintain physical activity in patients with COPD after a period of pulmonary rehabilitation.

@ERSpublications

mHealth intervention does not improve or maintain physical activity in COPD patients after pulmonary rehabilitation http://ow.ly/SS2T301BA85

This article has supplementary material available from erj.ersjournals.com

Received: Jan 122016 | Accepted after revision: June 172016 | First published online: Sept 012016

Support statement: A grateful acknowledgement goes to the Foundation Innovation Alliance (SIA RAAK) for co-funding the trial (project number: 2010-11-12P). Funding information for this article has been deposited with the Open Funder Registry.

Conflict of interest: Disclosures can be found alongside this article at erj.ersjournals.com

Copyright CERS 2016 


\section{Introduction}

Patients with chronic obstructive pulmonary disease (COPD) demonstrate reduced daily physical activity compared to healthy age-matched controls [1]. Both the amount and intensity of physical activity is reduced [2] and data suggest that the physical activity of patients is reduced early in the course of the disease [3]. Physical inactivity worsens over time [4], has important clinical consequences and undoubtedly complicates the course of the disease $[3,5]$.

Functional exercise capacity is known to improve in COPD patients during a pulmonary rehabilitation programme [6], but this effect declines over time [7] when patients do not continue to exercise after completing the programme [8].

The effect of pulmonary rehabilitation on physical activity yields inconsistent results [3, 6]. A 24-week course of pulmonary rehabilitation seems beneficial compared with 12 weeks, and an exercise programme lasting 18 months resulted in greater improvements than a 12 -week programme $[9,10]$. However, most pulmonary rehabilitation programmes only last for 8-12 weeks [11] and structured aftercare programmes are often lacking [5]. Hence there is a need for effective interventions aiming to improve, and subsequently maintain, physical activity in patients with COPD during, and particularly after, pulmonary rehabilitation [12]. Of the various interventions aimed to prolong the beneficial effects of pulmonary rehabilitation none have unequivocally been shown to work [13]. There is some evidence that health technology can help to facilitate change in physical activity behaviour [14]. It is expected that the developments in information and communication technology and the proficiency of future patients will have a significant impact [5], making mobile (m)Health support programmes accessible to patients. The inclusion of accelerometers in mobile phones and the increasing availability of mobile technology further facilitates such developments.

This study aims to test the efficacy of a previously developed mHealth intervention [15] in a randomised controlled trial. The primary aim is to study whether this mHealth intervention, started after discharge from a 12-week pulmonary rehabilitation programme, will enhance or maintain physical activity compared to usual care in patients with COPD. The secondary aim is to study whether these improvements would affect functional exercise capacity, health-related quality of life (HRQoL) and body mass index (BMI).

\section{Methods}

Design

This was a multicentre, investigator-blinded, randomised controlled trial with an intervention duration of 6 months. Participants were randomised into an intervention or usual care group. All participants gave written informed consent and continued to receive usual care according to the guidelines of the Dutch College of General Practitioners [16]. The study was approved by the Utrecht medical ethical research board (research protocol 11/279).

\section{Participants}

Physiotherapists in primary care physiotherapy practices with expertise in COPD were recruited at random throughout the Netherlands via the Utrecht network for COPD physiotherapists and an advertisement in a national physiotherapy journal (FysioPraxis). The physiotherapists subsequently recruited patients from their practice that were diagnosed with COPD, Global Initiative for Chronic Obstructive Lung Disease (GOLD) stage 2 or 3 (forced expiratory volume in $1 \mathrm{~s}$ (FEV1) 30-<80\%, FEV1/forced vital capacity (FVC) $<70 \%$ after bronchodilatation), aged $\geqslant 40$ years, who had completed a pulmonary rehabilitation programme of 3 months within the past 6 months and lived independently. Patients were not included in the trial if they were suffering from a comorbidity that greatly influences physical activity, using an assistive device for physical activity (e.g. walker or mobility scooter), intermittently ceased the pulmonary rehabilitation programme and/or experienced an exacerbation resulting in a hospital admission in the 6 months prior to the commencement of the study.

\section{Randomisation and intervention}

The patients included in the study were randomly assigned to the intervention or usual care group, independent of physiotherapy practice, based on a random number sequence generated in Excel (Microsoft, Redmond, WA, USA) before enrolment. These numbers ranged between 0 and 1 . The values were categorised into 0 (usual care) and 1 (intervention), based on a $\geqslant 0.5$ threshold. Subsequently, each newly recruited participant was given the first available number and enrolled in the corresponding group. Patients with and without long-term physiotherapy after pulmonary rehabilitation (some form of continued, though significantly reduced, supervised exercise training for 1-2 sessions a week versus no physiotherapy continuance) were separately randomised via stratification, because this was seen as a confounder.

All subjects received individual face-to-face (and written) instructions on the design of the study. Subjects in the usual care group solely performed the assessments at the four measurement time points. 
The intervention consisted of two components: 1) a smartphone application (online supplementary figure S1) and 2) a website for the physiotherapists (online supplementary figure S2) [15]. The application showed physical activity in real time in quantitative and qualitative form, measured by the accelerometer embedded in the smartphone (HTC desire A8181; HTC, Taoyuan, Taiwan). Subjects were persuaded to achieve their personalised physical activity goal by automated persuasive messages and an emoticon (pictorial representation of an emotion). The physiotherapists could monitor their patients via the (secure) website, which showed both the physical activity data from all the participants from their practice and a more detailed view of individual patients. The physiotherapist was able to adjust each patient's physical activity goal and send group or individual text messages. No automated adjustments of the physical activity goal were performed. Physiotherapists received individual face-to-face (and written) instruction on the functionalities of the website.

The intervention group received a smartphone, a phone/internet contract and an individual face-to-face (and written) instruction on the use of the smartphone and the application. The subjects in the intervention group were instructed to wear the smartphone in a pouch on their belt and use it as their usual phone. Those subjects in the possession of mobile phones were asked to transfer their SIM (subscriber identification module) card into the study smartphone. For the first week of the study, physical activity goals were not set, and subjects were instructed to perform their day-to-day activities as usual. Afterwards, initial personal physical activity goals were calculated using data from this baseline week as follows. 1) Average steps per day $+20 \%$ as daily step goal; 2) daily, the number of steps during the 30 most intensive minutes were counted and averaged into a value for a week. This latter value $+20 \%$ was set as the minimum required number of steps in 1 min to account for an intensive minute of physical activity; and 3 ) 30 intensive minutes performed per day, according to the Dutch healthy exercise norm [17]. After this initial physical activity goal setting, physiotherapists were given responsibility for physical activity goal adjustment. They could reduce or increase the amount and intensity of the physical activity goal via the website, based on the individual ability of their patient over time.

\section{Assessments}

Measurement time points were at 0, 3, 6 and 12 months (T0, T3, T6 and T12, respectively). Assessments were performed by two researchers that were blinded to the group allocation.

\section{Lung function}

FEV1 and FVC were measured using a Spiromed 2000 (Medikro, Finland). Spirometry was performed according to American Thoracic Society/European Respiratory Society guidelines [18], and the results were compared to normal values of QuANJER et al. [19].

\section{Functional exercise capacity}

The modified 6-min walk test (6MWT) was performed on a 10-m course using methodology suggested for primary care [20]. 6MWTs were performed twice at each measurement time point (with a period of rest in between), and the best score was used for analysis. The results were expressed as percentage of the predicted normal values for the Dutch population [21].

HRQOL

Subjects completed the self-administered standardised chronic respiratory questionnaire (CRQ-SAS). The questionnaire has been found to be a reproducible, reliable and stable measure of health status [22]. In addition, it has been found to be reliable and valid in the Dutch language [23].

\section{Physical activity}

Each subject was provided with an accelerometer validated in patients with COPD (SenseWear PRO or MF-SW mini armband; Body Media, Pittsburgh, USA) [24]. This device was worn according to the manufacturer's instructions. Subjects were asked to wear the armband during waking hours (except for water-related activities) for seven successive days after each measurement time point.

Physical activity was analysed using proprietary software (SenseWear version 7.1).

\section{$B M I$}

Height was measured only at baseline. Weight was measured at all visits.

\section{Weather}

For each assessment, humidity, atmospheric pressure and temperature of a meteorological point nearest to the location of the physiotherapy practice were noted from a Dutch meteorological website (http://archivenl.com/page/1421607/2013-02-17/http://www.meteo24.nl/nl/index.php?go=6,1). 


\section{Statistical analysis}

Descriptive statistics include the mean \pm SD or frequency, where appropriate. Power calculations revealed the need for 70-80 subjects per group to be sufficient to achieve satisfactory power (online supplementary material A).

Average steps per weekday was the main outcome measure and was computed as suggested by DEMEYER et al. [25]. Using repeated measures linear mixed modelling (LMM), we assessed the differences between groups, the effects of measurement time points and whether group differences were dependent on measurement time points (group by time interaction). If this latter group by time interaction is not significant, then the development of the outcome measure over time is similar in both groups, and there is no effect of the intervention. The chosen approach was a random intercept, random slope method with an unstructured covariance matrix. The primary explanatory parameters were the measurement time points (T0-12) and the group allocation (intervention/usual care). These two parameters constitute the basic model. Subsequently, other parameters were added to see if they improved the model. Online supplementary material B describes the LMM analysis in more detail. This analysis process was repeated with the 6-min walking distance (6MWD), average metabolic equivalent of task (METs), CRQ-SAS outcomes and BMI as outcome measures.

Adherence to the intervention was measured as the percentage of days the intervention was used, and as percentage of days the physical activity goal was obtained. Analyses were performed using SPSS for Windows (IBM, PASW Statistics, version 23.0, Chicago, IL, USA).

\section{Results}

157 subjects started the study, and 121 subjects completed all four measurements (figure 1). Subjects were recruited from 32 physiotherapy practices throughout the Netherlands; 14 within and 18 outside the province of Utrecht. Baseline characteristics of the subjects in the intervention and usual care groups are presented in table 1 . Results on weather are presented in online supplementary material C.

The average personal physical activity goal was $6124 \pm 2819$ steps per day at the start of the study and $5968 \pm 2442$ steps per day at the end of the intervention period. The intervention was used on $89 \pm 18.5 \%$ of the study days. The personal physical activity goal was obtained on $34 \pm 16 \%$ of these days (figure 2). On average, subjects achieved $10 \pm 25 \%$ steps per day less than indicated in their physical activity goal. Physiotherapists sent 362 personal and 10 group messages to their patients. The patients returned 162 messages to the physiotherapists. In the intervention group, FEV1 decreased at an average of $56 \mathrm{~mL}$ over the 1-year follow-up period $(\mathrm{p}=0.162)$ and $98 \mathrm{~mL}$ in the usual care group $(\mathrm{p}=0.001)$. There was no group by time interaction $(p=0.508)$, meaning that the decline in FEV1 over time was not significantly different between the groups.

The effect sizes of the measurement time points and added parameters that significantly improved the models are presented in online supplementary material C. Table 2 shows the results of the LMM analyses for the outcome measures (additional information on the outcomes is shown in online supplementary table S11).

\section{Primary outcome}

On average, subjects wore the armband for $6.6 \pm 0.76$ days per week. Overall, physical activity as assessed by steps per weekday decreased over time $(\mathrm{p}<0.001)$, but no group by time interaction $(\mathrm{p}=0.811)$ nor group effect was observed $(\mathrm{p}=0.934)$. These data show that both groups declined over time in a similar way (figure 3 ). There was no group by time interaction between subjects receiving long-term physiotherapy after pulmonary rehabilitation and those subjects without long-term physiotherapy $(p=0.266)$, meaning that this did not have any effect on the results in this study.

There was no significant decrease in average METs over time $(p=0.07)$ and no differences between the groups $(\mathrm{p}=0.22)$. The group by time interaction was also nonsignificant $(\mathrm{p}=0.36)$.

\section{Secondary outcomes}

Functional exercise capacity

The 6MWD did not show a significant group by time interaction $(\mathrm{p}=0.585)$, significant decrease over time $(\mathrm{p}=0.53)$, nor group effect $(\mathrm{p}=0.485)$.

HRQOL

Only fatigue showed a significant group by time interaction, whereas the other variables did not. However, this was probably caused by great variability in the data rather than the intervention (figure 4). No significant differences were found between the groups at each individual measurement time point for 


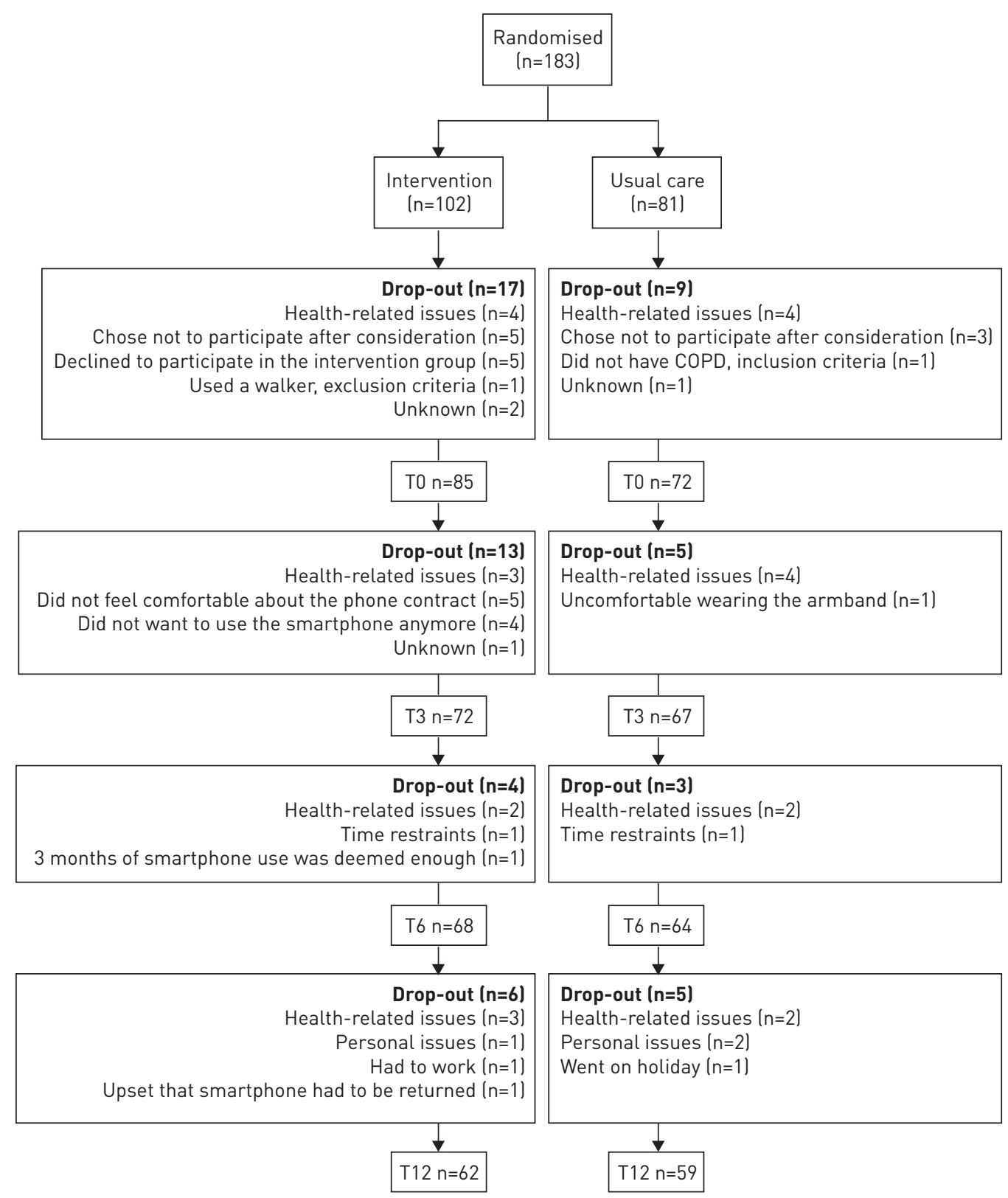

FIGURE 1 Consort diagram for patient retention in the study. COPD: chronic obstructive pulmonary disease; T0: 0 months; T3: 3 months; T6: 6 months; T12: 12 months.

fatigue. There was significantly less dyspnoea at $\mathrm{T} 3(\mathrm{p}=0.01)$, and a lower emotional function at $\mathrm{T} 0$ $(\mathrm{p}=0.04)$ and T6 $(\mathrm{p}=0.02)$ compared with T12. Mastery significantly diminished over time $(\mathrm{p}=0.017)$, but fatigue did not. There were no significant group differences for all CRQ-SAS outcomes.

$B M I$

The group by time interaction of BMI was not significant. BMI was significantly higher at T6 $(p=0.02)$, but this was not clinically relevant. There were no differences between the groups.

\section{Discussion}

The present study shows that an mHealth intervention using a smartphone with support from a primary care physiotherapist did not improve or maintain physical activity in patients with COPD following pulmonary rehabilitation. In addition, the intervention did not affect functional exercise capacity, HRQoL outcomes (dyspnoea, fatigue, mastery and emotional function) or BMI. Our hypothesis that subjects in the intervention group would improve or maintain their physical activity through the benefit of real-time physical activity biofeedback, goal setting and motivational support from their physiotherapist could not 
TABLE 1 Baseline characteristics and demographics

\begin{tabular}{lcc} 
& Intervention & Usual care \\
\hline Subjects & 84 & 73 \\
Age years & $62 \pm 9$ & $63 \pm 8$ \\
Females/males & $42 / 42$ & $37 / 36$ \\
Body mass index & & \\
$\quad$ Underweight $<18.5 \mathrm{~kg} \cdot \mathrm{m}^{-2}$ & $1(1)$ & $2(3)$ \\
Normal 18.5-24.9 $\mathrm{kg} \cdot \mathrm{m}^{-2}$ & $24(30)$ & $27(37)$ \\
Overweight 25-29.9 $\mathrm{kg} \cdot \mathrm{m}^{-2}$ & $31(38)$ & $22(30)$ \\
Obese $\geqslant 30 \mathrm{~kg} \cdot \mathrm{m}^{-2}$ & $25(31)$ & $22(30)$ \\
FEV 1 L & $1.67 \pm 0.597$ & $1.48 \pm 0.43$ \\
FEV $\%$ pred & $59 \pm 20$ & $53 \pm 15$ \\
FVC L & $3.6 \pm 0.98$ & $3.48 \pm 0.98$ \\
FVC \% pred & $101 \pm 20$ & $99 \pm 19$ \\
6MWD m & $465 \pm 87$ & $459 \pm 73$ \\
6MWD \% pred & $80 \pm 15$ & $79 \pm 12$ \\
CRQ-SAS (score 1-7) & & \\
Dyspnoea & $4.8 \pm 1.3$ & $4.8 \pm 1.3$ \\
Fatigue & $4.3 \pm 1.1$ & $4.2 \pm 1.2$ \\
Emotional function & $5.0 \pm 1.1$ & $4.8 \pm 1.2$ \\
Mastery & $5.4 \pm 1.1$ & $5.3 \pm 1.1$ \\
Average steps per day (weekday) & $5824 \pm 3418$ & $5717 \pm 2870$ \\
Average steps per day (weekend) & $5219 \pm 3696^{+}$ & $5328 \pm 3424^{+}$ \\
Average METs & $1.48 \pm 0.39$ & $1.55 \pm 0.41$ \\
Long-term physiotherapy & $69(82)$ & $58(79)$ \\
\end{tabular}

Data are presented as $n$, mean \pm SD or $n(\%)$. FEV1: forced expiratory volume in $1 \mathrm{~s}$; FVC: forced vital capacity; 6MWD: 6-min walking distance; CRQ-SAS: self-administered standardised chronic respiratory questionnaire; MET: metabolic equivalent of task. "\#: three missing values for intervention; ": significantly higher than usual care; ${ }^{+}$: significantly lower than weekdays at $p<0.001$.

be confirmed. We found nine other studies that examined the effect of personalised feedback based on real-time objective data on physical activity in patients with COPD [12, 26-31]. All studies used external pedometers as a source of feedback on physical activity, and most of these studies were pilot studies with a short duration of intervention, which makes it difficult to draw any evidence-based conclusions on their long-term effectiveness. There were two larger studies with a long-term follow-up [32, 33]. Although both studies showed short-term effects, these were not maintained at the 1-year assessment. Physical activity

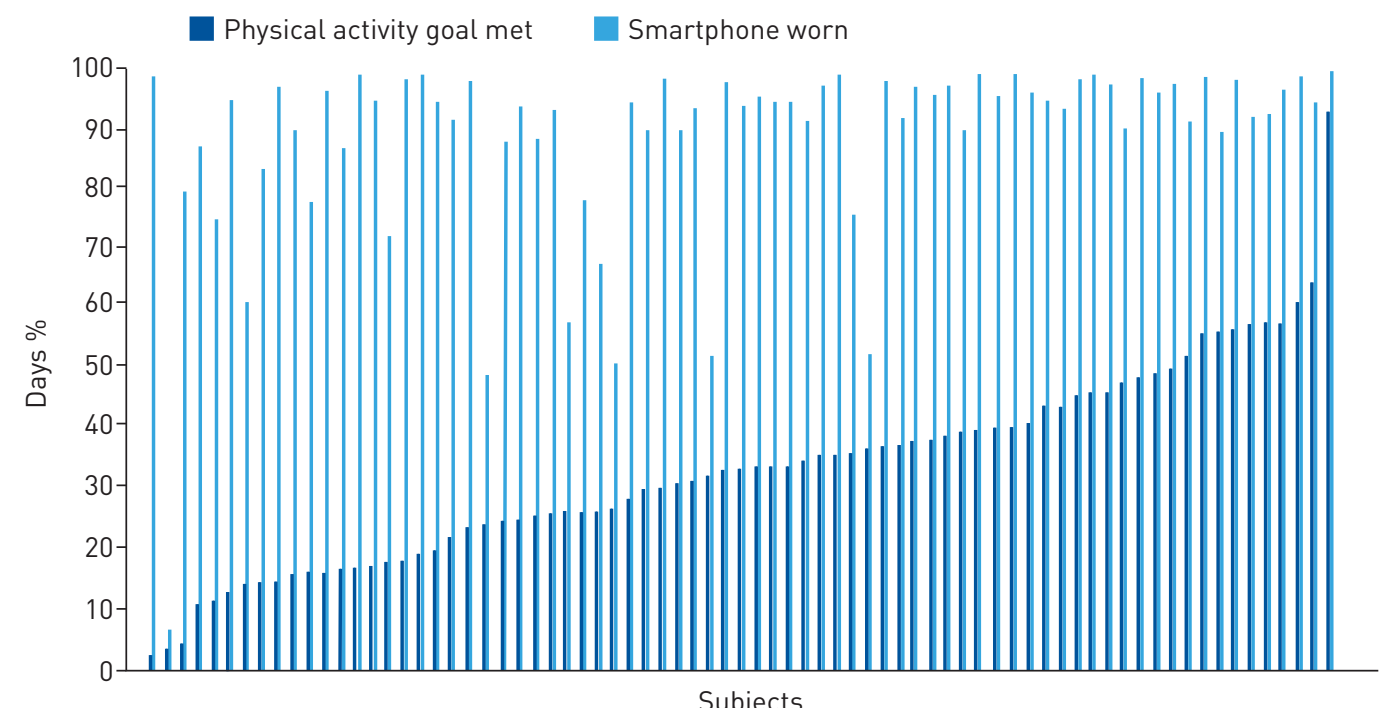

FIGURE 2 Percentage of days on which the physical activity goal was achieved, and smartphone worn per intervention group subject. 
TABLE 2 Results of the outcome measures

\begin{tabular}{|c|c|c|c|c|c|c|c|}
\hline & Tо & Change $^{\#}$ at T3 & Change $^{\#}$ at T6 & Change $^{\#}$ at T12 & $\begin{array}{c}\text { Subjects with } \geqslant 20 \% \\
\text { improvement at } \mathrm{T} 3 / \mathrm{T} 6 / \mathrm{T} 12\end{array}$ & $\begin{array}{c}\text { Subjects with } \geqslant 20 \% \\
\text { worsening at } \mathrm{T} 3 / \mathrm{T} 6 / \mathrm{T} 12\end{array}$ & p-value \\
\hline Average steps per weekday & & & & & & & 0.811 \\
\hline Intervention & $5717 \pm 418$ & $-512(-1003--21)$ & $-593(-1058--128)$ & $-1225(-1712--738)$ & $18 / 16 / 8(25 / 24 / 13)$ & $24 / 22 / 28(34 / 33 / 45)$ & \\
\hline Usual care & $6011 \pm 402$ & $-635(-1074--156)$ & $-833(-1315--352)$ & $-1148(-1651--644)$ & $9 / 12 / 12(13 / 19 / 20)$ & $22 / 23 / 27(32 / 35 / 45)$ & \\
\hline Average METs & & & & & & & 0.364 \\
\hline Intervention & $1.5 \pm 0.05$ & $-0.061(-0.15-0.03)$ & $-0.057(-0.15-0.04)$ & $-0.055(-0.15-0.04)$ & $8 / 9 / 4(11 / 13 / 7)$ & $8 / 10 / 5(11 / 15 / 8)$ & \\
\hline Usual care & $1.57 \pm 0.05$ & $-0.061(-0.15-0.03)$ & $0.021(-0.09-0.13)$ & $-0.105(-0.22-0.01)$ & $5 / 6 / 5(7 / 9 / 8)$ & $6 / 3 / 5(9 / 5 / 8)$ & \\
\hline 6MWD m & & & & & & & 0.585 \\
\hline Intervention & $456 \pm 14$ & $4.1(-2.8-11.1)$ & $4.8(-3.9-13.5)$ & $0.8(-8.8-10.3)$ & $2 / 2 / 3(2.8 / 3 / 4.8)$ & $0 / 0 / 1(0 / 0 / 1.6)$ & \\
\hline Usual care & $461 \pm 8$ & $1.9(-4.1-7.9)$ & $3.3(-2.9-9.6)$ & $4(-2.4-10.3)$ & & $0 / 0 / 1(0 / 0 / 1.7)$ & \\
\hline Dyspnoea (score 1-7) & & & & & & & 0.179 \\
\hline Intervention & $4.84 \pm 0.15$ & $0.17(-0.45-0.38)$ & $0.11(-0.14-0.35)$ & $-0.17(-0.44-0.09)$ & $11 / 14 / 12(16 / 21 / 19)$ & $5 / 10 / 17(7 / 15 / 27)$ & \\
\hline Usual care & $4.79 \pm 0.15$ & $0.01(-0.21-0.23)$ & $-0.13(-0.33-0.08)$ & $-0.08(-0.3-0.14)$ & 16/7/9 (24/11/15) & 9/7/6 (13/11/10) & \\
\hline Fatigue (score 1-7) & & & & & & & 0.018 \\
\hline Intervention & $4.35 \pm 0.1$ & $0.05(-0.15-0.26)$ & $-0.19(-0.39-0.01)$ & $-0.14(-0.35-0.07)$ & $14 / 10 / 7(20 / 15 / 11)$ & $7 / 13 / 14(10 / 19 / 22)$ & \\
\hline Usual care & $4.2 \pm 0.13$ & $-0.06(-0.28-0.17)$ & $0.13(-0.12-0.37)$ & $-0.12(-0.37-0.13)$ & $10 / 12 / 13(15 / 19 / 22)$ & $8 / 11 / 12(12 / 17 / 20)$ & \\
\hline Emotional function (score 1-7) & & & & & & & 0.590 \\
\hline Intervention & $4.93 \pm 0.09$ & $0.01(-0.14-0.16)$ & $-0.03(-0.18-0.12)$ & $0.09(-0.07-0.24)$ & 9/8/7 (13/12/11) & 4/10/8 (6/15/13) & \\
\hline Usual care & $4.76 \pm 0.13$ & $0.11(-0.04-0.27)$ & $0.04(-0.11-0.19)$ & $0.19(0.04-0.34)$ & 10/12/10 (15/19/17) & $5 / 8 / 5(7 / 12 / 8)$ & \\
\hline Mastery (score 1-7) & & & & & & & 0.154 \\
\hline Intervention & $5.42 \pm 0.09$ & $-0.03(-0.22-0.16)$ & $-0.14(-0.32-0.06)$ & $-0.1(-0.31-0.11)$ & $7 / 9 / 7(10 / 13 / 11)$ & $5 / 13 / 9(7 / 19 / 15)$ & \\
\hline Usual care & $5.35 \pm 0.09$ & $-0.06(-0.21-0.08)$ & $0.03(-0.13-0.19)$ & $-0.23(-0.39--0.06)$ & $6 / 8 / 6(9 / 12 / 10)$ & $5 / 3 / 8(7 / 5 / 1)$ & \\
\hline $\mathrm{BMI} \mathrm{kg} \cdot \mathrm{m}^{-2}$ & & & & & & & 0.458 \\
\hline Intervention & $27.7 \pm 0.58$ & $0.08(-0.11-0.26)$ & $0.12(-0.14-0.37)$ & $-0.05(-0.37-0.27)$ & & & \\
\hline Usual care & $26.7 \pm 0.6$ & $0.06(-0.13-0.26)$ & $0.32(0.07-0.57)$ & $0.09(-0.2-0.39)$ & & & \\
\hline
\end{tabular}




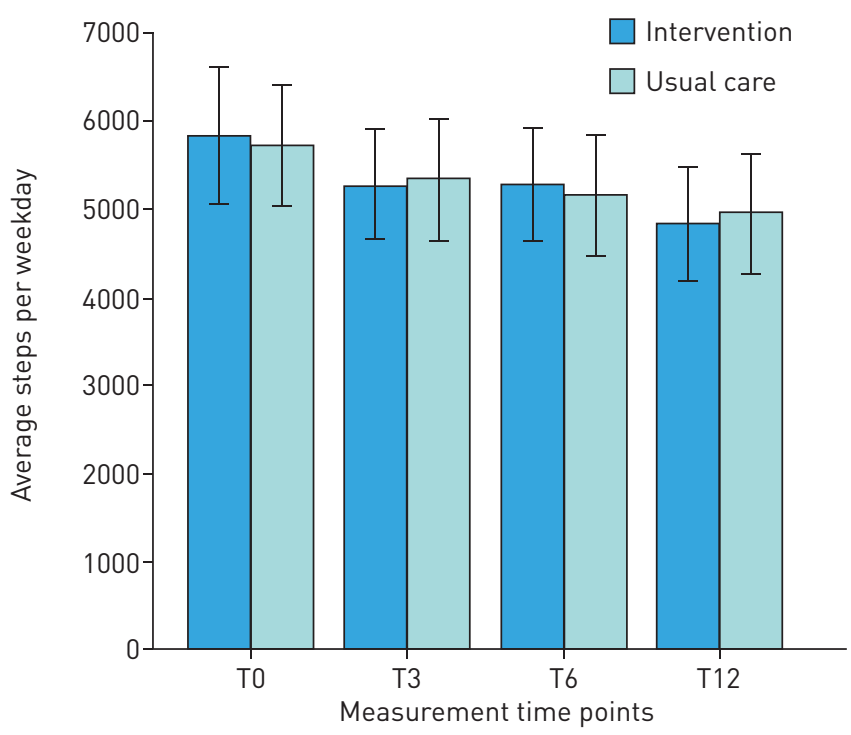

FIGURE 3 Average steps per weekday at the four measurement time points for the intervention and usual care groups. Data are presented as mean (95\% Cl). T0: 0 months; T3: 3 months; T6: 6 months; T12: 12 months.

level in COPD is consistently associated with mortality and exacerbations [34], stressing the importance of continuation of studies that are finding ways to improve or maintain physical activity in this patient group.

\section{Potential reasons for ineffectiveness of the intervention}

Smartphone as an interface and as a pedometer

Adherence in wearing the smartphone was high, at $89 \%$. However, on average, subjects only obtained their physical activity goal on $34 \%$ of the days they wore the smartphone and came $10 \%$ short of their physical activity goal throughout the intervention period. The interface of the smartphone to provide feedback intermediately on the actual physical activity level may not have been optimal, or its accuracy may have been insufficient. This could have reduced the motivation of subjects to adhere to the physical activity goal. Other forms of eHealth, such as telehealthcare, might offer better results with respect to physical activity. However, this remains unclear, as the heterogeneity of studies is high and only few report on physical activity outcomes [35].

\section{Involvement of physiotherapists}

Physiotherapists were instructed to monitor patients, send stimulating text messages or adjust physical activity goals when necessary. However, patients might have received insufficient support from their physiotherapists to adhere to the personalised physical activity goals. For example, physiotherapists did not send a lot of stimulating text messages. However, when indicators of website usage and physiotherapist characteristics were added to the LMM analyses, the model did not improve significantly (online

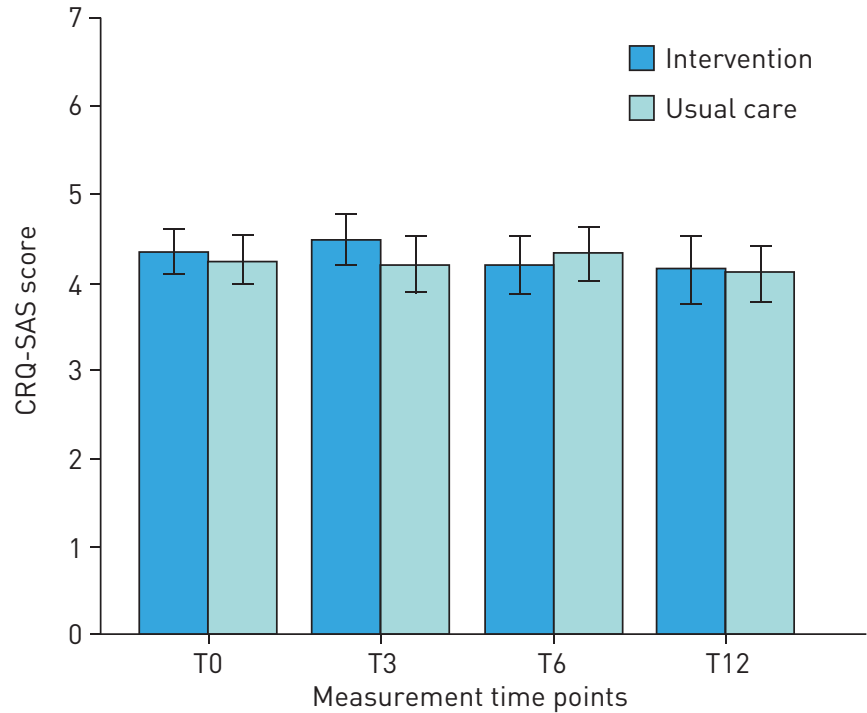

FIGURE 4 Group by time interaction for fatigue. Data are presented as mean $\quad(95 \% \quad \mathrm{Cl}) . \quad \mathrm{CRQ}-\mathrm{SAS}$ : self-administered standardised chronic respiratory questionnaire; T0: 0 months; T3: 3 months; T6: 6 months; T12: 12 months. 
supplementary material B). Furthermore, there was no difference in steps per weekday between subjects with long-term physiotherapy after pulmonary rehabilitation, thus receiving more attention from their physiotherapist, and those without long-term physiotherapy.

Digital and self-management skills

With a complex disease such as COPD, mHealth interventions could be a valuable addition to the multidisciplinary care offered to patients. Strong self-management skills, including the ability to act on incentives, could improve the efficacy of these interventions. Digital skills and the aid of healthcare practitioners would also help in this regard. It is possible that a large number of subjects in this study might have lacked the skill-set needed to fully benefit from our mHealth intervention. It might be interesting to see if these skill-sets can be measured in individual patients and taught in a personally tailored form. Learning self-management skills only during pulmonary rehabilitation does not seem to be sufficient [6], thus we should pay attention to how these skills can be maintained in the long-term. It is nevertheless plausible that during the pulmonary rehabilitation programme, time could be set aside to learn how to use the mHealth application and take appropriate actions when prompted. This was not done in the present study.

\section{Subject selection}

The intervention might have yielded different results in patients that did not complete a pulmonary rehabilitation programme. As there could be more room for improvement, physical activity levels could have increased. This has been shown in previous pedometer studies [12,31]. Nevertheless, as the intervention was not successful in maintaining physical activity in patients after pulmonary rehabilitation, the question remains whether it is capable of improving physical activity in patients without pulmonary rehabilitation.

Physical activity decreased significantly over time, as did lung function and mastery. Physical activity decreased on average by 889 steps per weekday over the 1-year duration of the study, which is more than double what was found in previous reports [4]. It is possible that patients had increased their physical activity by the end of the 3-month outpatient rehabilitation programme preceding the study [25] and subsequently decreased their activity back to their pre-rehabilitation physical activity. In any case, our intervention could not prevent this from happening. A study that followed patients over 12 months after a pulmonary rehabilitation programme showed that, as in our study, physical activity declined. Past exercise habits, 6MWD and barriers to exercise were determinants that discriminated between patients that declined significantly during follow-up, and those that remained at a high or a low activity level [36]. These outcomes might be able to discriminate between patients that are in need of additional attention from a physiotherapist and patients that are able to maintain their physical activity with less support.

Surprisingly, functional exercise capacity remained unchanged over the study duration of 1 year. This is in contrast to other studies where the 6MWD deteriorated over time in post-rehabilitation COPD patients [37-39]. Our results indicate that subjects remained at the same capacity level, but became less active during daily life; this holds true for patients with and without long-term physiotherapy after pulmonary rehabilitation.

eHealth is a relatively new area in healthcare, and it has many potential benefits. Nonetheless, this study shows that in a population of patients with COPD, mHealth interventions are not always effective and expectations have to be adjusted. Future studies should try to identify those factors that influence the usability and efficacy of mHealth interventions. It is not only important to look at disease-specific factors, but also at individual factors, as the population of COPD patients comprises a wide variety of persons with varying needs, abilities and wishes.

\section{Limitations}

Subjects

Drop-out in the intervention group was higher (39\% in the intervention group versus $27 \%$ in the usual care group), and it was also higher among females. Initial worries about the telephone contract (linked to a personal bank account) and fear of losing the device were reasons for patients to drop out of the study. After the consent form was adjusted to state explicitly that there would not be any financial ramifications, the drop-out rate decreased.

There were patients who still had trouble using the smartphone, even after the individual face-to-face (and written) instructions and the availability of a helpdesk. Because smartphones are becoming more common, this will probably be less of a problem in the future.

Patients with GOLD stage 4 disease were not included in the study, resulting in a sample not fully similar to other pulmonary rehabilitation studies. This was because their low physical activity level renders an intervention effect improbable. 


\section{Physiotherapists}

After initial instruction, the physiotherapists were no longer prompted to use the mHealth intervention (they did have access to a help centre). This was by design to see how the intervention would work in practice. As an indication, physiotherapists were told to monitor the website at least once a week. Multiple instructions/more prompting might have increased monitoring/stimulation from physiotherapists and, subsequently, positively influenced patient outcomes.

The present study was set up in primary care and did not measure outcomes at the start of the pulmonary rehabilitation programme. This makes it difficult to compare the decline in physical activity with the potentially beneficial effects of the preceding pulmonary rehabilitation programme.

\section{Conclusion}

Compared to usual care, no differences were observed in physical activity, functional exercise capacity, HRQoL outcomes or BMI in patients with COPD using a consumer smartphone-based mHealth intervention geared to enhance physical activity with support from a primary care physiotherapist following pulmonary rehabilitation. There was a significant decrease over time in physical activity, mastery and lung function, but not in functional exercise capacity. Our mHealth intervention did not succeed in enabling patients with COPD to prevent a decrease in physical activity.

\section{Acknowledgements}

We would like to thank Chantal Huisman, Angelo Antonietti, Ansam Barakat, Jamie van Dalum, Lisa Esteban Lopez, Vincent Keijzer and Jeroen Frank (University of Applied Sciences Utrecht, Utrecht, the Netherlands) for their assistance in executing the trial. We would also like to thank Saïda de Vries and Sonja Barends (University of Applied Sciences Utrecht, Utrecht, the Netherlands) for their assistance with the administration of the trial. The Utrecht network for COPD physiotherapists and the FysioPraxis journal helped us to recruit physiotherapist practices to participate in the trial.

\section{References}

1 Vorrink SN, Kort HS, Troosters T, et al. Level of daily physical activity in individuals with COPD compared with healthy controls. Respir Res 2011; 12: 33.

2 Pitta F, Troosters T, Spruit MA, et al. Characteristics of physical activities in daily life in chronic obstructive pulmonary disease. Am J Respir Crit Care Med 2005; 171: 972-977.

3 Watz H, Pitta F, Rochester CL, et al. An official European Respiratory Society statement on physical activity in COPD. Eur Respir J 2014; 44: 1521-1537.

4 Waschki B, Kirsten AM, Holz O, et al. Disease progression and changes in physical activity in patients with chronic obstructive pulmonary disease. Am J Respir Crit Care Med 2015; 192: 295-306.

5 Hartman JE, Boezen HM, de Greef MH, et al. Consequences of physical inactivity in chronic obstructive pulmonary disease. Expert Rev Respir Med 2010; 4: 735-745.

6 Egan C, Deering BM, Blake C, et al. Short term and long term effects of pulmonary rehabilitation on physical activity in COPD. Respir Med 2012; 106: 1671-1679.

7 Foglio K, Bianchi L, Bruletti G, et al. Long-term effectiveness of pulmonary rehabilitation in patients with chronic airway obstruction. Eur Respir J 1999; 13: 125-132.

8 Gross NJ. Extrapulmonary effects of chronic obstructive pulmonary disease. Curr Opin Pulm Med 2001; 7: 84-92.

9 Verrill D, Barton C, Beasley W, et al. The effects of short-term and long-term pulmonary rehabilitation on functional capacity, perceived dyspnea, and quality of life. Chest 2005; 128: 673-683.

10 Berry MJ, Rejeski WJ, Adair NE, et al. A randomized, controlled trial comparing long-term and short-term exercise in patients with chronic obstructive pulmonary disease. J Cardiopulm Rehabil 2003; 23: 60-68.

11 Longfonds. Longrevalidatie. [Pulmonary Rehabilitation]. www.longfonds.nl/copd/behandeling-van-copd/longrevalidatie Date last accessed: March 31, 2015.

12 Mendoza L, Horta P, Espinoza J, et al. Pedometers to enhance physical activity in COPD: a randomised controlled trial. Eur Respir J 2015; 45: 347-354.

13 Fahy BF. Promoting long-term benefits of pulmonary rehabilitation: the role of reducing the impact of respiratory exacerbations. Clin Chest Med 2014; 35: 429-437.

14 Smith SM, Elkin SL, Partridge MR. Technology and its role in respiratory care. Prim Care Respir J 2009; 18 : 159-164.

15 Vorrink SN, Kort HS, Troosters T, et al. A mobile phone app to stimulate daily physical activity in patients with chronic obstructive pulmonary disease: development, feasibility, and pilot studies. JMIR Mhealth Uhealth 2016; 4: e11.

16 The Dutch College of General Practitioners. Guidelines 2015. www.nhg.org/dutch-college-general-practitioners Date last accessed: April 7, 2015.

17 Wendel-Vos G. Normen van lichamelijke (in)activiteit [Standards of Physical (In)activity.] In: Volksgezondheid Toekomst Verkenning, Nationaal Kompas Volksgezondheid. Bilthoven, RIVM, 2014. www.nationaalkompas.nl/ gezondheidsdeterminanten/leefstij//lichamelijke-activiteit/normen-van-lichamelijke-in-activiteit/\#definition_1347 Date last accessed: August 28, 2015. Date last updated: June 23, 2014.

18 Miller MR, Hankinson J, Brusasco V, et al. Standardisation of spirometry. Eur Respir J 2005; 26: 319-338.

19 Quanjer PH, Tammeling GJ, Cotes JE, et al. Lung volumes and forced ventilatory flows. Report Working Party Standardization of Lung Function Tests, European Community for Steel and Coal. Official Statement of the European Respiratory Society. Eur Respir J 1993; 6: Suppl. 16, 5-40.

20 Beekman E, Mesters I, Hendriks EJ, et al. Course length of 30 metres versus 10 metres has a significant influence on six-minute walk distance in patients with COPD: an experimental crossover study. J Physiother 2013; 59: 169-176.

21 Beekman E, Mesters I, Gosselink R, et al. The first reference equations for the 6-minute walk distance over a $10 \mathrm{~m}$ course. Thorax 2014; 69: 867-868. 
22 Williams JE, Singh SJ, Sewell L, et al. Development of a self-reported Chronic Respiratory Questionnaire (CRQ-SR). Thorax 2001; 56: 954-959.

23 Rutten-van Mölken M, Roos B, Van Noord JA. An empirical comparison of the St George's Respiratory Questionnaire (SGRQ) and the Chronic Respiratory Disease Questionnaire (CRQ) in a clinical trial setting. Thorax 1999; 54: 995-1003.

24 van Remoortel H, Raste Y, Louvaris Z, et al. Validity of six activity monitors in chronic obstructive pulmonary disease: A comparison with indirect calorimetry. PLOS ONE 2012; 7: e39198.

25 Demeyer H, Burtin C, Van Remoortel H, et al. Standardizing the analysis of physical activity in patients with COPD following a pulmonary rehabilitation program. Chest 2014; 146: 318-327.

26 Tabak M, Vollenbroek-Hutten MM, van der Valk PD, et al. A telerehabilitation intervention for patients with chronic obstructive pulmonary disease: a randomized controlled pilot trial. Clin Rehabil 2014; 28: 582-591.

27 Verwey R, van der Weegen S, Spreeuwenberg M, et al. A pilot study of a tool to stimulate physical activity in patients with COPD or type 2 diabetes in primary care. J Telemed Telecare 2014; 20: 29-34.

28 Liu WT, Wang CH, Lin HC, et al. Efficacy of a cell phone-based exercise programme for COPD. Eur Respir J 2008; 32: 651-659.

29 Nguyen HQ, Gill DP, Wolpin S, et al. Pilot study of a cell phone-based exercise persistence intervention post-rehabilitation for COPD. Int J Chron Obstruct Pulmon Dis 2009; 4: 301-313.

30 Hospes G, Bossenbroek L, Ten Hacken NH, et al. Enhancement of daily physical activity increases physical fitness of outclinic COPD patients: results of an exercise counseling program. Patient Educ Couns 2009; 75: 274-278.

31 de Blok BM, de Greef $\mathrm{MH}$, ten Hacken $\mathrm{NH}$, et al. The effects of a lifestyle physical activity counseling program with feedback of a pedometer during pulmonary rehabilitation in patients with COPD: a pilot study. Patient Educ Couns 2006; 61: 48-55.

32 Steele BG, Belza B, Cain KC, et al. A randomized clinical trial of an activity and exercise adherence intervention in chronic pulmonary disease. Arch Phys Med Rehabil 2008; 89: 404-412.

33 Moy ML, Collins RJ, Martinez CH, et al. An internet-mediated pedometer-based program improves health-related quality-of-life domains and daily step counts in COPD: a randomized controlled trial. Chest 2015; 148: 128-137.

34 Gimeno-Santos E, Frei A, Steurer-Stey C, et al. Determinants and outcomes of physical activity in patients with COPD: a systematic review. Thorax 2014; 69: 731-739.

35 Lundell S, Holmner A, Rehn B, et al. Telehealthcare in COPD: a systematic review and meta-analysis on physical outcomes and dyspnea. Respir Med 2015; 109: 11-26.

36 Soicher JE, Mayo NE, Gauvin L, et al. Trajectories of endurance activity following pulmonary rehabilitation in COPD patients. Eur Respir J 2012; 39: 272-278.

37 Cortopassi F, Celli B, Divo M, et al. Longitudinal changes in handgrip strength, hyperinflation and 6-minute walk distance in patients with COPD and a control group. Chest 2015; 148: 986-994.

38 Heppner PS, Morgan C, Kaplan RM, et al. Regular walking and long-term maintenance of outcomes after pulmonary rehabilitation. J Cardiopulm Rehabil 2006; 26: 44-53.

39 Brooks D, Krip B, Mangovski-Alzamora S, et al. The effect of postrehabilitation programmes among individuals with chronic obstructive pulmonary disease. Eur Respir J 2002; 20: 20-29. 